\title{
Manufacturing Strategy for Multiwalled Carbon Nanotubes as a Biocompatible and Innovative Material
}

\author{
Hisao Haniu, ${ }^{1}$ Naoto Saito, ${ }^{2}$ Yoshikazu Matsuda, ${ }^{3}$ Yuki Usui, ${ }^{4}$ \\ Kaoru Aoki, ${ }^{5}$ Masayuki Shimizu, ${ }^{5}$ Nobuhide Ogihara, ${ }^{5}$ Kazuo Hara, ${ }^{5}$ \\ Seiji Takanashi, ${ }^{5}$ Masanori Okamoto, ${ }^{5}$ Koichi Nakamura, ${ }^{5}$ Norio Ishigaki, ${ }^{5}$ \\ Tamotsu Tsukahara, ${ }^{6}$ and Hiroyuki Kato ${ }^{5}$ \\ ${ }^{1}$ Institute of Carbon Science and Technology, Shinshu University, 3-1-1 Asahi, Matsumoto, Nagano 390-8621, Japan \\ ${ }^{2}$ Department of Applied Physical Therapy, Shinshu University School of Health Sciences, Nagano 390-8621, Japan \\ ${ }^{3}$ Clinical Pharmacology Educational Center, Nihon Pharmaceutical University, Saitama 362-0806, Japan \\ ${ }^{4}$ Research Center for Exotic Nanocarbons, Shinshu University, Nagano 390-8621, Japan \\ ${ }^{5}$ Department of Orthopaedic Surgery, Shinshu University School of Medicine, Nagano 390-8621, Japan \\ ${ }^{6}$ Department of Integrative Physiology and Bio-System Control, Shinshu University School of Medicine, Nagano 390-8621, Japan
}

Correspondence should be addressed to Hisao Haniu, hhaniu@shinshu-u.ac.jp

Received 29 June 2011; Accepted 26 August 2011

Academic Editor: Lifeng Dong

Copyright (C) 2012 Hisao Haniu et al. This is an open access article distributed under the Creative Commons Attribution License, which permits unrestricted use, distribution, and reproduction in any medium, provided the original work is properly cited.

\begin{abstract}
We investigated the relationship between differences in multiwalled carbon nanotubes (MWCNTs) and the biological responses they elicit in order to develop biocompatible MWCNTs. We exposed human bronchial epithelial (BEAS-2B) cells to two sizes and six grades of MWCNTs and measured the resulting cell viability, total reactive oxygen and/or nitrogen species (tROS/RNS) production, and cytokine secretion. Although differences in cellular tROS production were associated with differences in grades of MWCNTs, the graphitization temperature of MWCNTs apparently did not influence tROS production. However, cell viability was affected by MWCNT graphitization temperature and diameter. Moreover, cytokine secretion was apparently affected by treatment temperature, but not MWCNT diameter. We concluded that the highest temperature resulted in the most biocompatibility because impurities and carbon defects were removed from the MWCNTs. However, other mechanisms are possible. Therefore, it is important to optimize each type of MWCNT by monitoring biological responses that type elicits during the manufacturing stage for applications involving biology and medicine.
\end{abstract}

\section{Introduction}

Due to their unique properties, MWCNTs have potential applications in a wide variety of industries including biomedical fields [1]. Many uses for MWCNTs have been proposed including biosensors, drug and vaccine delivery vehicles, and novel biomaterials [2]. However, before such biomaterials can be incorporated into new and existing biomedical devices, the biocompatibility of MWCNTs must be thoroughly investigated because Takagi et al. and Poland et al. reported that mice injected intraperitoneally with MWCNTs exhibited toxicological responses similar to those seen in mice exposed to asbestos [3, 4]. Although some investigators have investigated the safety of inhalation or intratracheal administration of MWCNTs in vivo, a clear conclusion cannot be drawn from the results of these experiments [5-9]. Similarly, results from in vitro studies do not provide a consistent picture of the safety of MWCNTs; some studies indicate that MWCNTs cause cytotoxicity and cytokine production [10-12], but others indicate that MWCNTs did not cause any significant biological responses $[13,14]$.

It is a crucial to determine whether MWCNTs cause inflammation when used as a biomaterial. Oxidant stress is thought to be a likely cause of some possible MWCNTmediated biological responses. Therefore, oxidative stress, as a cause of inflammation, attracts attention, and the transition metal catalyst residues CNTs might be major 
TABLE 1: Basic properties of MWCNTs.

\begin{tabular}{|c|c|c|c|c|c|c|c|}
\hline \multirow{2}{*}{$\begin{array}{l}\text { MWCNT type } \\
\text { abbreviation name }\end{array}$} & \multicolumn{6}{|c|}{ MWCNT-150 } & \multirow{2}{*}{ Testing method } \\
\hline & NT15 & $\mathrm{NT} 15+\mathrm{Fe}$ & NT15-30 & NT15-26 & NT15-22 & NT15-13 & \\
\hline Graphitization temperature $\left({ }^{\circ} \mathrm{C}\right)$ & $3000^{\mathrm{b}}$ & $3000^{b}$ & $3000^{c}$ & $2600^{c}$ & $2200^{c}$ & - & \\
\hline Additional treatment & - & $\mathrm{Fe}_{2} \mathrm{O}_{3}{ }^{\mathrm{d}}$ & - & - & - & - & \\
\hline Diameter $(\mathrm{nm})$ & \multicolumn{6}{|c|}{150} & FE-SEM \\
\hline Length $(\mu \mathrm{m})$ & \multicolumn{6}{|c|}{$7-10$} & FE-SEM \\
\hline Iron content (ppm) & 34 & 730 & $<20$ & $<20$ & 60 & 13000 & ICP-MS \\
\hline$R$ value $\left(I_{\mathrm{d}} / I\right)^{\mathrm{a}}$ & 0.3 & 0.3 & 0.2 & 0.5 & 0.9 & 1.4 & Raman spectroscopy $(785 \mathrm{~nm})$ \\
\hline MWCNT type & \multicolumn{6}{|c|}{ MWCNT-80 } & \multirow{2}{*}{ Testing method } \\
\hline abbreviation name & NT08 & $\mathrm{NT} 08+\mathrm{Fe}$ & NT08-30 & NT08-26 & NT08-22 & NT08-13 & \\
\hline Graphitization temperature $\left({ }^{\circ} \mathrm{C}\right)$ & $3000^{\mathrm{b}}$ & $3000^{\mathrm{b}}$ & $3000^{c}$ & $2600^{c}$ & $2200^{c}$ & - & \\
\hline Additional treatment & - & $\mathrm{Fe}_{2} \mathrm{O}_{3}{ }^{\mathrm{d}}$ & - & - & - & - & \\
\hline Diameter $(\mathrm{nm})$ & \multicolumn{6}{|c|}{80} & FE-SEM \\
\hline Length $(\mu \mathrm{m})$ & \multicolumn{6}{|c|}{$7-10$} & FE-SEM \\
\hline Iron content (ppm) & 1700 & 2200 & $<20$ & $<20$ & 360 & 21000 & ICP-MS \\
\hline$R$ value $\left(I_{\mathrm{d}} / I\right)^{\mathrm{a}}$ & \multicolumn{6}{|c|}{$\mathrm{n} / \mathrm{a}$} & Raman spectroscopy $(785 \mathrm{~nm})$ \\
\hline
\end{tabular}

${ }^{a} R$ refers to the intensity of $\mathrm{D}$ band over the intensity of $\mathrm{G}$ band.

${ }^{b}$ MWCNTs were heated at Showa denko.

${ }^{\mathrm{c}}$ MWCNTs were heated in our laboratory.

${ }^{\mathrm{d}} \mathrm{NT} 15$ and NT08 were added $\mathrm{Fe}_{2} \mathrm{O}_{3}$ (1000: 1), mixed, and sonicated in $0.02 \%$ triton-X100 solution. Then, they were filtered and dried at $120^{\circ} \mathrm{C}$. $\mathrm{n} / \mathrm{a}=$ not available.

cause of oxidative stress $[15,16]$. It is known that the impurities in MWCNTs before graphitization (We named the MWCNTs "As-grown.") can be removed by thermal treatment for graphitization, and MWCNTs produced for commercial uses are additionally heat treated. In fact, we reported that the heat-treated MWCNTs did not represent cell proliferation inhibition although As-grown MWCNTs indicated cytotoxicity on U937 human monoblastic leukemia cells [17]. However, U937 cells do not endocytose MWCNTs, and the results were different for a human bronchial epithelial cell line (BEAS-2B cells), which endocytoses heat-treated MWCNTs [18]. BEAS-2B cells are of bronchial epithelium cell origin and are susceptible to cytotoxicity.

In this study, we examined cytotoxicity, oxidative stress, and inflammation, as for index of biological responses, using two sizes of MWCNTs with varying iron concentration in BEAS-2B cells to clarify more important factor during the manufacturing stage to improve the biocompatibility.

\section{Materials and Methods}

2.1. Carbon Nanotubes. We used commercial MWCNT materials, vapor-grown carbon fiber (VGCF, Showa Denko, Tokyo, Japan) and vapor-grown carbon fiber-S (VGCF-S, Showa Denko, Tokyo, Japan), that were manufactured by a chemical vapor deposition method [19], and As-grown MWCNTs before the graphitization were also provided by Showa Denko. Information on each type of MWCNT, including the abbreviated name (e.g., NT15, NT08), additional treatments in our laboratory, and properties, is listed in Table 1. MWCNTs were sterilized in an autoclave at $121^{\circ} \mathrm{C}$ for 15 min. MWCNTs were vortexed for $1 \mathrm{~min}$ in PBS (-) containing $0.1 \%$ gelatin (Nacalai Tesque, Kyoto, Japan) and sonicated with a water-bath sonicator for $30 \mathrm{~min}$. Dispersed

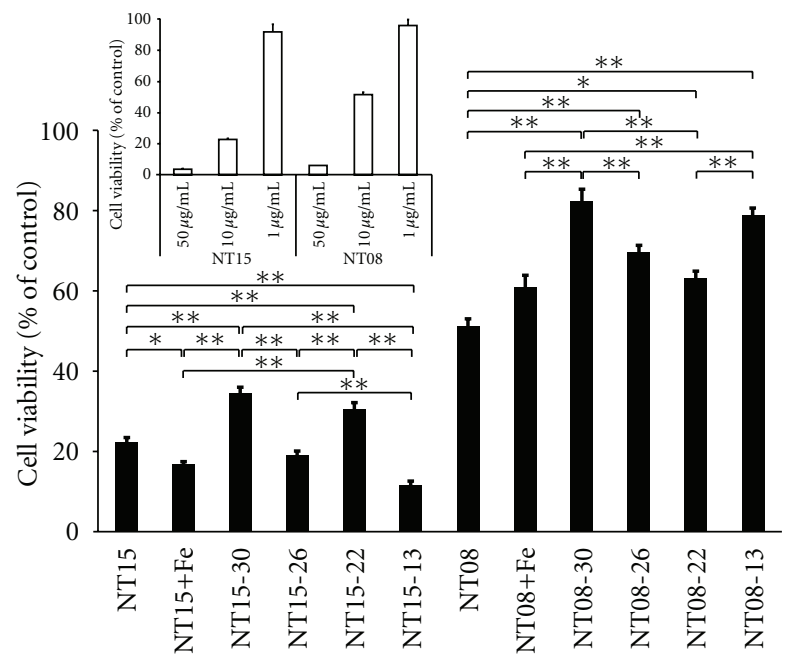

FIGURE 1: The viability of BEAS-2B cells treated with different MWCNTs. The cells were exposed to MWCNTs for $24 \mathrm{~h}$. The small graph shows the dose effects of NT15 and NT08 on the cell viability. The large graph shows the cell viability associated with $10 \mu \mathrm{g} / \mathrm{mL}$ treatment of each MWCNT in the MWCNT-150 and MWCNT-80 series. (Mean $\pm \mathrm{SE}, n=6,{ }^{*} P<0.05,{ }^{* *} P<0.01$.)

MWCNTs suspended in the PBS-gelatin dispersant were added to cell culture medium at $1 / 100$ volume in each of the following experiments.

2.2. Cell Culture. The human bronchial epithelial cell line, BEAS-2B, was purchased from the American Type Culture Collection (Manassas, Va, USA). BEAS-2B cells were cultured in Ham's nutrient mixture F-12 with $10 \%$ fetal bovine serum at $37^{\circ} \mathrm{C}$ in a $5 \% \mathrm{CO}_{2}$ humidified incubator and passaged 


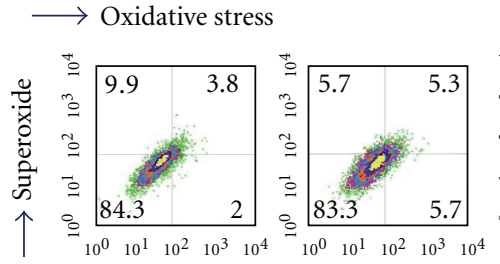

Control

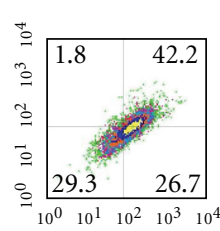

Pyocyanin

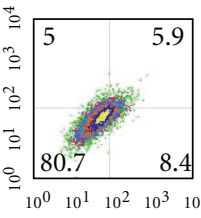

$\mathrm{NT} 15+\mathrm{Fe}$

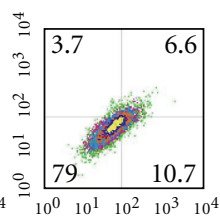

NT08

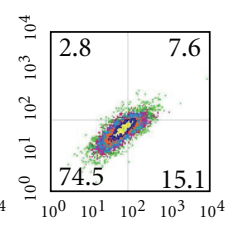

$\mathrm{NT} 08+\mathrm{Fe}$

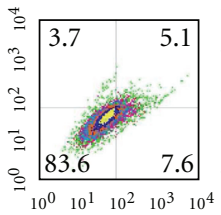

NT15-30

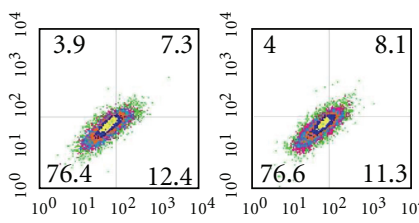

NT08-30

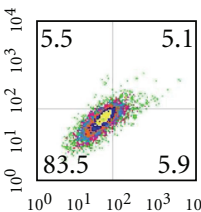

NT15-26

NT08-26

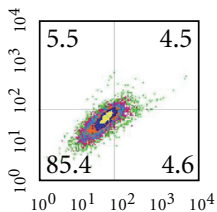

NT15-22

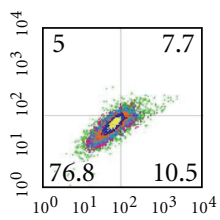

NT08-22

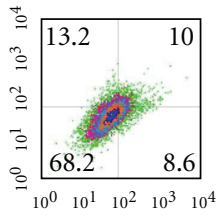

NT15-13

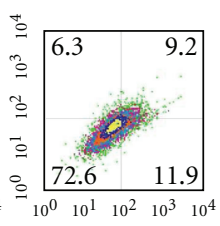

NT08-13

FIgURE 2: The tROS production in BEAS-2B cells treated with different MWCNTs. The cells were exposed to MWCNTs for 1 or $24 \mathrm{~h}$, then stained with two color ROS detection reagents, and analyzed using FCM. Image shows the cell population of the fraction separated by oxidative stress and superoxide for $1 \mathrm{~h}$ (10,000 cells). The numbers in the image reflect the percentage of the cell population in each quadrant.

twice each week. For each study, the cells were seeded at a density of $5 \times 10^{5}$ cells/mL and adhered for $24 \mathrm{~h}$.

2.3. Alamar Blue $(A B)$ Assay. To assess the viability of cells exposed to different MWCNTs, we performed an Alamar blue assay (AlamarBlue cell viability reagent; Invitrogen, Carlsbad, Calif, USA), according to the manufacturer's instructions. Cells were plated in 96-well plates and incubated for $24 \mathrm{~h}$ at $37^{\circ} \mathrm{C}$ in the culture medium containing VGCF in dispersant or only dispersant control medium. Viable cells metabolized the dye, resulting in an increase of fluorescence following excitation/emission at 550/600 nm with a fluorescence multiplate reader (PowerScan 4, DS Pharma Biomedical, Osaka, Japan). Cytotoxic activity was calculated as follows: percent cytotoxicity $=100 \times$ experimental value/control value. Test media were assayed six times for each treatment condition.

2.4. Total ROS/Superoxide Production. To determine total reactive oxygen and/or nitrogen species (tROS/RNS) production in the cells exposed to MWCNTs, we used a total ROS/superoxide detection kit (Enzo Life Sciences, Plymouth Meeting, Pa, USA). Cells were plated into 24 -well plates and incubated for $24 \mathrm{~h}$ so cells could adhere to the substrate. Cells were then incubated for 1 or $24 \mathrm{~h}$ at $37^{\circ} \mathrm{C}$ in the presence or absence of MWCNTs. Pyocyanin $(100 \mu \mathrm{M})$ was used as a reactive oxygen species (ROS) inducer. Following exposing to MWCNTs, the cells were treated with oxidative stress detection reagent (OSDR) and superoxide detection reagent (SDR) for $30 \mathrm{~min}$. Cells were then washed once in $1 \times$ wash buffer and harvested with trypsin-EDTA. Finally, the cells were suspended with $0.3 \mathrm{~mL}$ of $10 \%$ FBS in $1 \times$ wash buffer and passed through nylon mesh. These cells were subjected to flow cytometry (FCM; FACSCalibur, Becton Dickinson, San Jose, Calif, USA) in the FL1 channel for OSDR signals and FL2 channel for SDR signals. The cells were separated into four fractions, and the fractions were named tROS (FL1 and FL2 positive), superoxide (FL1 negative and FL2 positive), peroxide (FL1 positive and FL2 negative), and negative (FL1 and FL2 negative).

2.5. Cytokine Measurement. Cytokines in the culture supernatant were measured by a BD cytometric bead array flex set assay (Human soluble protein master buffer kit \& Human IL-6 and IL-8 flex sets; BD Biosciences, San Jose, Calif, USA), according to the manufacturer's protocol Briefly, BEAS-2B cells that had been cultured in 24-well plate for $24 \mathrm{~h}$ were exposed to $10 \mu \mathrm{g} / \mathrm{mL}$ of MWCNT in dispersant for $24 \mathrm{~h}$, and the resulting supernatant was collected by centrifugation. Then cytokine capture beads (for IL-6 and IL-8) were mixed with supernatant samples or cytokine standards in FCM tubes. The mixtures were vortexed, and antibody for fluorescence detection was added to each tube. The samples were then incubated at room temperature for $2 \mathrm{~h}$. Following incubation, beads were washed once by wash buffer and resuspended prior to reading with an FCM.

2.6. Statistical Analysis. Data are presented as mean \pm SE. Statistical significant was determined by analysis of variance (ANOVA) followed by the Student's $t$-test to compare the controls with each sample, and the Tukey-Kramer method for comparisons between different types of MWCNTs. $P<$ 0.05 was considered statistically significant.

\section{Results}

3.1. Cell Viability. Cell viability was measured using $A B$ assay method. The viability value for each experimental sample was expressed as percentage of the control sample, which was designated as $100 \%$ viable (Figure 1). NT15 and NT08 which are commercial MWCNTs decreased the cell viability depending on the concentration. At a concentration of $10 \mu \mathrm{g} / \mathrm{mL}$, all MWCNTs in the NT08 series were associated with a viability associated higher than that associated with MWCNTs in the NT15 series. Moreover, commercial MWCNTs (NT15 and NT08) were associated with lower 
TABLE 2: Fractionation rate using two fluorescent reagents for tROS/RNS with FCM on BEAS-2B cells exposed to MWCNTs at 1 and 24 h.

(a) Fractionation rate (\%) of 10,000 cells at $1 \mathrm{~h}($ mean \pm SE, $n=3)$

\begin{tabular}{|c|c|c|c|c|c|c|c|}
\hline Fraction & Control & NT15 & $\mathrm{NT} 15+\mathrm{Fe}$ & NT15-30 & NT15-26 & NT15-22 & NT15-13 \\
\hline tROS & $3.8 \pm 0.4$ & $5.3 \pm 0.7$ & $5.9 \pm 0.4$ & $5.1 \pm 0.6$ & $5.1 \pm 0.2$ & $4.5 \pm 0.3$ & $10.0 \pm 0.2$ \\
\hline Superoxide & $9.9 \pm 0.2$ & $5.7 \pm 0.1$ & $5.0 \pm 0.6$ & $3.7 \pm 0.2$ & $5.5 \pm 0.5$ & $5.5 \pm 0.7$ & $13.2 \pm 2.2$ \\
\hline Peroxide & $2.0 \pm 0.2$ & $5.7 \pm 1.2$ & $8.4 \pm 1.3$ & $7.6 \pm 1.4$ & $5.9 \pm 0.7$ & $4.6 \pm 0.9$ & $8.6 \pm 1.3$ \\
\hline Negative & $84.3 \pm 0.3$ & $83.3 \pm 1.8$ & $80.7 \pm 1.2$ & $83.6 \pm 2.0$ & $83.5 \pm 0.3$ & $85.4 \pm 0.7$ & $68.2 \pm 1.0$ \\
\hline Fraction & Pyocyanin & NT08 & $\mathrm{NT} 08+\mathrm{Fe}$ & NT08-30 & NT08-26 & NT08-22 & NT08-13 \\
\hline tROS & $42.2 \pm 2.1$ & $6.6 \pm 0.8$ & $7.6 \pm 0.6$ & $7.3 \pm 0.6$ & $8.1 \pm 0.3$ & $7.7 \pm 0.8$ & $9.2 \pm 0.4$ \\
\hline Superoxide & $1.8 \pm 0.3$ & $3.7 \pm 0.5$ & $2.8 \pm 0.3$ & $3.9 \pm 1.0$ & $4.0 \pm 0.7$ & $5.0 \pm 0.8$ & $6.3 \pm 0.7$ \\
\hline Peroxide & $26.7 \pm 1.5$ & $10.7 \pm 0.8$ & $15.1 \pm 1.6$ & $12.4 \pm 2.5$ & $11.3 \pm 1.6$ & $10.5 \pm 2.0$ & $11.9 \pm 1.4$ \\
\hline Negative & $29.3 \pm 2.6$ & $79.0 \pm 1.3$ & $74.5 \pm 1.9$ & $76.4 \pm 1.9$ & $76.6 \pm 1.0$ & $76.8 \pm 2.0$ & $72.6 \pm 0.9$ \\
\hline
\end{tabular}

(b) Statistical significance compared between different types of MWCNTs by the Tukey-Kramer method ( $m e a n \pm \operatorname{SE}, n=3, * P<0.05$, ** $P<0.01$ )

\begin{tabular}{|c|c|c|}
\hline Fraction & MWCNT-150 & MWCNT-80 \\
\hline \multirow{2}{*}{ tROS } & Control versus NT15+Fe*, NT15-13** & \multirow{2}{*}{$\begin{array}{l}\text { Control versus NT08+Fe*, NT08-30*, NT08-26**, } \\
\text { NT08-22*, NT08-13** }\end{array}$} \\
\hline & $\begin{array}{l}\text { NT15-13 versus NT15**, NT15+Fe**, NT15-30**, } \\
\text { NT15-26**, NT15-22** }\end{array}$ & \\
\hline \multirow[t]{2}{*}{ Superoxide } & $\begin{array}{l}\text { Conrol versus NT15**, NT15+Fe*, NT15-30**, NT15-26**, } \\
\text { NT15-22* }\end{array}$ & $\begin{array}{l}\text { Control versus NT08**, NT08+Fe**, NT08-30*, NT08-26*, } \\
\text { NT08-22*, NT08-13*, }\end{array}$ \\
\hline & $\begin{array}{l}\text { NT15-13 versus NT15**, NT15+Fe**, NT15-30**, } \\
\text { NT15-26**, NT15-22** }\end{array}$ & NT08+Fe versus NT08-13* \\
\hline Peroxide & Control versus NT15+Fe*, NT15-26*, NT15-13* & Conrol versus NT08**, NT08+Fe*, NT08-26*, NT08-13* \\
\hline \multirow{2}{*}{ Negative } & Control versus NT15-13* & \multirow{2}{*}{ Conrol versus NT08*, NT08+Fe*, NT08-26*, NT08-13** } \\
\hline & $\begin{array}{l}\text { NT15-13 versus NT15**, NT15+Fe**, NT15-30**, } \\
\text { NT15-26**, NT15-22** }\end{array}$ & \\
\hline
\end{tabular}

(c) Fractionation rate (\%) of 3,000 or fewer cells at $24 \mathrm{~h}($ mean $\pm \mathrm{SE}, n=3$ )

\begin{tabular}{|c|c|c|c|c|c|c|c|}
\hline Fraction & Control & $\mathrm{NT} 5^{\#}$ & $\mathrm{NT} 15+\mathrm{Fe}^{\#}$ & NT15-30\# & NT15-26 & NT15-22 & NT15-13 \\
\hline tROS & $3.4 \pm 2.1$ & $6.3 \pm 0.6$ & $7.1 \pm 0.6$ & $11.1 \pm 1.8$ & $7.0 \pm 0.4$ & $7.4 \pm 0.9$ & $18.9 \pm 3.4$ \\
\hline Superoxide & $5.9 \pm 0.3$ & $17.9 \pm 2.6$ & $14.5 \pm 1.0$ & $19.8 \pm 2.0$ & $17.7 \pm 3.2$ & $17.6 \pm 2.6$ & $20.1 \pm 1.7$ \\
\hline Peroxide & $2.0 \pm 1.5$ & $4.7 \pm 0.2$ & $7.3 \pm 0.6$ & $8.9 \pm 0.9$ & $5.8 \pm 0.2$ & $5.5 \pm 1.0$ & $8.9 \pm 1.8$ \\
\hline Negative & $88.7 \pm 3.5$ & $71.1 \pm 2.1$ & $71.2 \pm 1.6$ & $60.2 \pm 4.2$ & $69.5 \pm 3.1$ & $69.5 \pm 1.9$ & $52.1 \pm 3.8$ \\
\hline Fraction & Pyocyanin & NT08 & $\mathrm{NT} 08+\mathrm{Fe}$ & NT08-30 & NT08-26 & NT08-22 & NT08-13 \\
\hline tROS & $50.5 \pm 2.3$ & $9.9 \pm 1.0$ & $9.9 \pm 2.3$ & $9.6 \pm 2.2$ & $10.1 \pm 1.8$ & $9.9 \pm 1.3$ & $10.7 \pm 1.5$ \\
\hline Superoxide & $20.8 \pm 0.7$ & $21.5 \pm 1.9$ & $17.6 \pm 1.4$ & $17.3 \pm 1.6$ & $25.3 \pm 1.3$ & $28.7 \pm 2.5$ & $41.7 \pm 3.1$ \\
\hline Peroxide & $1.3 \pm 0.1$ & $4.2 \pm 0.8$ & $5.6 \pm 1.3$ & $4.3 \pm 1.6$ & $3.0 \pm 0.6$ & $2.5 \pm 0.4$ & $1.4 \pm 0.4$ \\
\hline Negative & $27.4 \pm 1.7$ & $64.5 \pm 0.3$ & $66.9 \pm 2.3$ & $68.8 \pm 2.2$ & $61.6 \pm 1.4$ & $58.9 \pm 0.9$ & $46.2 \pm 1.4$ \\
\hline
\end{tabular}

\# = less than 3,000 cells.

cell viability than the MWCNTs treated thermally in our laboratory for each series except the NT15-26. Based on these observations, MWCNT treatment temperature was apparently not directly related to cell viability, indicating that the impurities (i.e., mainly iron) and/or carbon defects were not the principal cause of cytotoxicity. Interestingly, NT15 MWCNTs were associated with higher viability than NT15+Fe and NT15-13, which both contain substantial amounts of iron, but NT08 MWCNTs were associated with lower cell viability than NT08+Fe and NT08-13.

3.2. tROS/RNS Production. Generally, cellular tROS/RNS are produced and eliminated rapidly. However, we assayed tROS/RNS at $1 \mathrm{~h}$ and at $24 \mathrm{~h}$ after exposing cells to MWCNTs because the cells internalized MWCNTs over time. Only 3,000 or fewer cells were assayed for the $24 \mathrm{~h}$ time point because the cells were injured, but we assayed 10,000 cells at the $1 \mathrm{~h}$ time point. Figure 2 and Tables 2(a) and 2(b) show each fraction of the population resulting from FCM analysis. At $1 \mathrm{hr}$, the fraction of tROS-positive cells was significantly higher in NT15+Fe and the MWCNT-80 series without NT08 than in the control samples. However, the tROS-positive fractions were no higher in the experimental sample than in the pyocyanin sample, which was a positive control. At $1 \mathrm{hr}$, the superoxide-positive fraction was significantly lower in all experimental samples than in the control sample, except that the superoxide-positive fraction in NT15-13 sample was not significantly different from that in the control sample. 
Although the peroxide-positive fraction of cells treated with some grades of MWCNTs was significantly higher than that of the control cells, the values were consistently less than half of the values associated with the pyocyanin samples. The alteration of MWCNT-80 series was larger than that of MWCNT-150 series in the peroxide-positive fractions. NT15-13 MWCNTs were significantly different from the MWCNT-150 series in the tROS, superoxide, and negative fractions, and there was a significant difference between only NT08+Fe and NT08-13 in the MWCNT-80 series for the superoxide fraction. The cell counts from the $24 \mathrm{~h}$ timepoint were too low to result in statistically significant differences; nevertheless, we present the results as reference data (Table 2(c)). At $24 \mathrm{hr}$, the tROS, superoxide, and peroxide fractions were larger in all MWCNT-treated cells than in control cells, and the tROS and superoxide fractions were larger in all $24 \mathrm{~h}$ samples than in the $1 \mathrm{~h}$ samples.

3.3. Cytokine Secretion. Recently, we reported that BEAS-2B cells exposed to MWCNTs secreted IL-6 and IL-8 [18]. All MWCNT treatments resulted in significant increased IL-6 and IL- 8 secretions when compared to the control treatment, and all, except NT15-30, resulted in higher IL-8 secretion than did LPS, which was a positive control (Figure 3). There were statistically significant differences in the MWCNT150 series though there were no significant differences in the MWCNT-80 series. However, secretion associated with NT15-30 and NT15-13 in the MWCNT-150 series and with NT08-30 and NT08-13 in MWCNT-80 tended to be lower than that with other MWCNTs in the respective series for both cytokines.

\section{Discussion}

Carbon nanotubes (CNTs) are expected to be useful for a wide variety of industrial applications, and postprocessing procedures will depend on the individual application. In the biomedical field, the research on drug delivery systems and diagnostic imaging that use CNTs is advanced $[20,21]$. However, doubts about efficacy and safety of modified CNT remain [22], and the influence of different manufacturing processes for CNTs, as biomaterials, has not been examined thoroughly. In this study, we evaluated the influence of different graphitization temperatures on the MWCNTs of two different diameters.

The graphitization temperature has a crucial influence on the impurities content and crystalline of MWCNTs, and these factors are reportedly critical for the safety of CNTs [23-25]. However, our results did not indicate that carbon defects and impurities directly affected three biological responses, cell viability, tROS production, and cytokine secretion. Each biological response did not show mutual relativity and did not correlate to impurities or the defects, although both the MWCNT-150 and MWCNT-80 series had fewer defects and impurities depending on the treatment temperature. However, the diameter of MWCNTs did affect cell viability and tROS production. MWCNT- 80 series gave rise to the seemingly contradictory results that relative cell

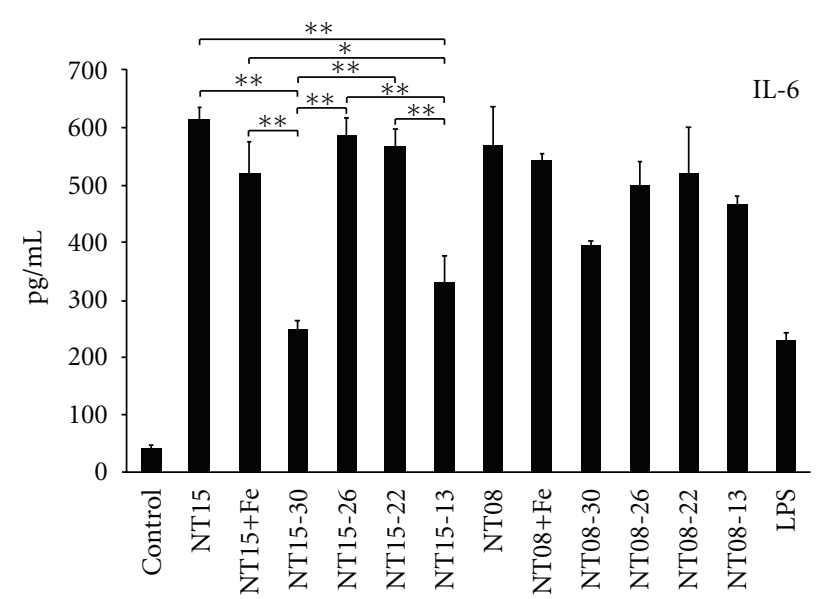

(a)

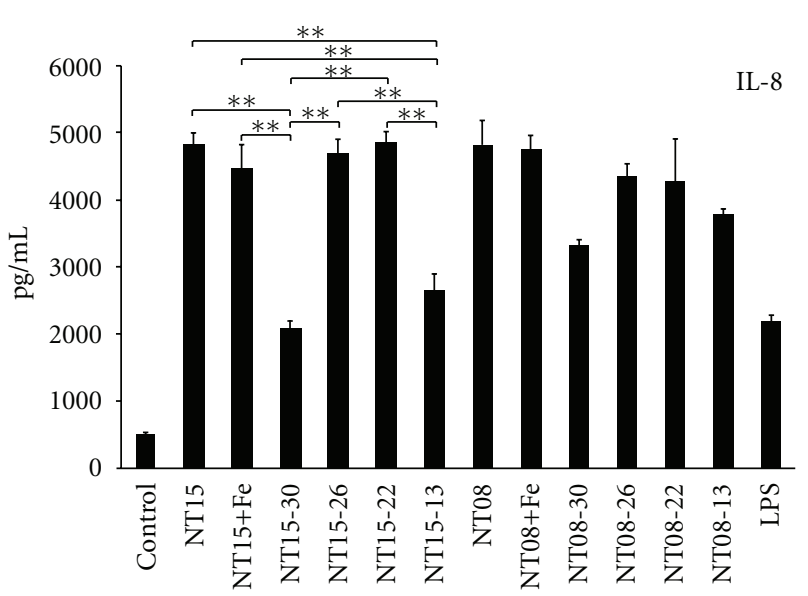

(b)

FIgURE 3: The cytokine secretion from BEAS-2B cells treated with different MWCNTs. The cells were exposed to MWCNTs for $24 \mathrm{~h}$. The upper graph shows IL-6 secretion, and the lower graph shows IL-8 secretion from cells treated with $10 \mu \mathrm{g} / \mathrm{mL}$ of each MWCNT, the MWCNT-150 and MWCNT-80 series (mean \pm SE, $n=3, * P<$ $\left.0.05,{ }^{*} P<0.01\right)$.

viability was high while tROS production was also high. Therefore, cellular tROS production may have been critical to cytotoxicity. IL-6 and IL-8 secretion increased with all MWCNT exposure regardless of the MWCNT diameter, and secretion associated with NT15-30 and NT15-13 and NT08-30 and NT08-13, treatments tended to be lower than secretion associated with treatments involving MWCNT of the same diameter. However, the data from NT15-30 or NT08-30 treated with graphitization at $3000^{\circ} \mathrm{C}$ and NT-13 or NT08-13 without graphitization were not able to clarify commonalities in this research. Additional iron did not affect the biological responses of original MWCNTs except for the cell viability counts associated with the N15 and $\mathrm{N} 15+\mathrm{Fe}$ treatments. These results also indicated that the iron contained in the MWCNTs is not crucial because the cell viability of NT15-13, which included 13,000 ppm iron, was the lowest in the MWCNT-150 series, but NT08-13, which included 21,000 ppm iron, was associated with high 
viability. Finally, the MWCNTs processed at the maximum temperature in the lab had the highest biocompatibility overall regardless of diameter.

In this study, we found that the graphitization temperature of MWCNTs in the manufacturing process affected biological response to the MWCNTs, but the biological responses did not have regularity and was affected by the diameter of the MWCNTs. In other words, we should investigate the condition that results in the lowest biological responses for each MWCNT in the manufacturing process before that MWCNT is used for applications in biology and medicine. It is our duty to optimize the biocompatibility of the nanomaterial itself in order to develop application for the nanomaterials.

\section{Acknowledgments}

The authors thank the staff of the Division of Instrumental Analysis in the Research Center for Human and Environmental Sciences of the Shinshu University for their help. This research was supported by the Program for Fostering Regional Innovation in Nagano and a Grant-in-Aid (no. 19002007) from the Ministry of Education, Culture, Sports, Science and Technology of Japan.

\section{References}

[1] M. Endo, M. S. Strano, and P. M. Ajayan, "Potential applications of carbon nanotubes," Topics in Applied Physics, vol. 111, pp. 13-61, 2008.

[2] N. Saito, Y. Usui, K. Aoki et al., "Carbon nanotubes: biomaterial applications," Chemical Society Reviews, vol. 38, no. 7, pp. 1897-1903, 2009.

[3] C. A. Poland, R. Duffin, I. Kinloch et al., "Carbon nanotubes introduced into the abdominal cavity of mice show asbestoslike pathogenicity in a pilot study," Nature Nanotechnology, vol. 3, no. 7, pp. 423-428, 2008.

[4] A. Takagi, A. Hirose, T. Nishimura et al., "Induction of mesothelioma in $\mathrm{p} 53+/$ - mouse by intraperitoneal application of multi-wall carbon nanotube," Journal of Toxicological Sciences, vol. 33, no. 1, pp. 105-116, 2008.

[5] N. Kobayashi, M. Naya, M. Ema et al., "Biological response and morphological assessment of individually dispersed multi-wall carbon nanotubes in the lung after intratracheal instillation in rats," Toxicology, vol. 276, no. 3, pp. 143-153, 2010.

[6] H. Ellinger-Ziegelbauer and J. Pauluhn, "Pulmonary toxicity of multi-walled carbon nanotubes (Baytube $(\mathrm{R})$ ) relative to $\alpha$ quartz following a single $6 \mathrm{~h}$ inhalation exposure of rats and a 3 months post-exposure period," Toxicology, vol. 266, no. 1-3, pp. 16-29, 2009.

[7] L. Ma-Hock, S. Treumann, V. Strauss et al., "Inhalation toxicity of multiwall carbon nanotubes in rats exposed for 3 months," Toxicological Sciences, vol. 112, no. 2, pp. 468-481, 2009.

[8] D. W. Porter, A. F. Hubbs, R. R. Mercer et al., "Mouse pulmonary dose- and time course-responses induced by exposure to multi-walled carbon nanotubes," Toxicology, vol. 269, no. 2-3, pp. 136-147, 2010.

[9] J. Muller, M. Delos, N. Panin, V. Rabolli, F. Huaux, and D. Lison, "Absence of carcinogenic response to multiwall carbon nanotubes in a 2-year bioassay in the peritoneal cavity of the rat," Toxicological Sciences, vol. 110, no. 2, pp. 442-448, 2009.

[10] S. Hirano, Y. Fujitani, A. Furuyama, and S. Kanno, "Uptake and cytotoxic effects of multi-walled carbon nanotubes in human bronchial epithelial cells," Toxicology and Applied Pharmacology, vol. 249, no. 1, pp. 8-15, 2010.

[11] L. Tabet, C. Bussy, N. Amara et al., "Adverse effects of industrial multiwalled carbon nanotubes on human pulmonary cells," Journal of Toxicology and Environmental Health Part A, vol. 72, no. 2, pp. 60-73, 2009.

[12] N. A. Monteiro-Riviere, R. J. Nemanich, A. O. Inman, Y. Y. Wang, and J. E. Riviere, "Multi-walled carbon nanotube interactions with human epidermal keratinocytes," Toxicology Letters, vol. 155, no. 3, pp. 377-384, 2005.

[13] M. De Nicola, D. M. Gattia, S. Bellucci et al., "Effect of different carbon nanotubes on cell viability and proliferation," Journal of Physics Condensed Matter, vol. 19, no. 39, Article ID 395013, pp. 395013-395019, 2007.

[14] K. Pulskamp, S. Diabate, and H. F. Krug, "Carbon nanotubes show no sign of acute toxicity but induce intracellular reactive oxygen species in dependence on contaminants," Toxicology Letters, vol. 168, no. 1, pp. 58-74, 2007.

[15] L. Guo, D. G. Morris, X. Liu, C. Vaslet, R. H. Hurt, and A. B. Kane, "Iron bioavailability and redox activity in diverse carbon nanotube samples," Chemistry of Materials, vol. 19, no. 14, pp. 3472-3478, 2007.

[16] V. E. Kagan, Y. Y. Tyurina, V. A. Tyurin et al., "Direct and indirect effects of single walled carbon nanotubes on RAW 264.7 macrophages: role of iron," Toxicology Letters, vol. 165, no. 1, pp. 88-100, 2006.

[17] H. Haniu, Y. Matsuda, K. Takeuchi, Y. A. Kim, T. Hayashi, and M. Endo, "Proteomics-based safety evaluation of multi-walled carbon nanotubes," Toxicology and Applied Pharmacology, vol. 242, no. 3, pp. 256-262, 2010.

[18] T. Tsukahara and H. Haniu, "Cellular cytotoxic response induced by highly purified multi-wall carbon nanotube in human lung cells," Molecular and Cellular Biochemistry, vol. 352, pp. 57-63, 2011.

[19] M. Endo, "Grow carbon fibers in the vapor phase," Chemtech, vol. 18 , no. 9, pp. 568-576, 1988.

[20] V. S. Thakare, M. Das, A. K. Jain, S. Patil, and S. Jain, "Carbon nanotubes in cancer theragnosis," Nanomedicine, vol. 5, no. 8 , pp. 1277-1301, 2010.

[21] S. R. Ji, C. Liu, B. Zhang et al., "Carbon nanotubes in cancer diagnosis and therapy," Biochimica et Biophysica Acta, vol. 1806, no. 1, pp. 29-35, 2010.

[22] G. Pastorin, "Crucial functionalizations of carbon nanotubes for improved drug delivery: a valuable option?" Pharmaceutical Research, vol. 26, no. 4, pp. 746-769, 2009.

[23] I. Fenoglio, G. Greco, M. Tomatis et al., "Structural defects play a major role in the acute lung toxicity of multiwall carbon nanotubes: physicochemical aspects," Chemical Research in Toxicology, vol. 21, no. 9, pp. 1690-1697, 2008.

[24] J. Muller, F. Huaux, A. Fonseca et al., "Structural defects play a major role in the acute lung toxicity of multiwall carbon nanotubes: toxicological aspects," Chemical Research in Toxicology, vol. 21, no. 9, pp. 1698-1705, 2008.

[25] X. Hu, S. Cook, P. Wang, H. M. Hwang, X. Liu, and Q. L. Williams, "In vitro evaluation of cytotoxicity of engineered carbon nanotubes in selected human cell lines," Science of the Total Environment, vol. 408, no. 8, pp. 1812-1817, 2010. 

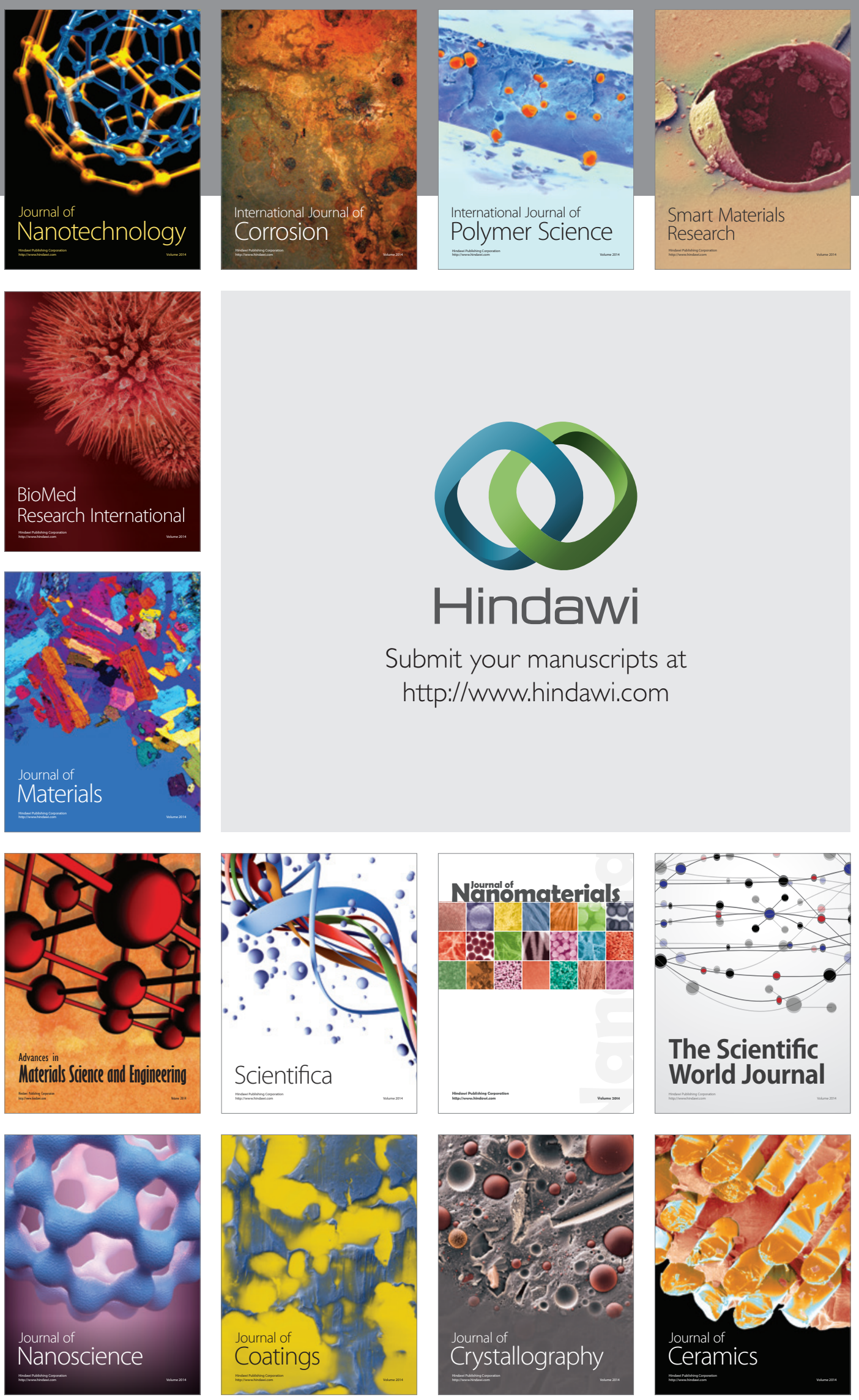

The Scientific World Journal

Submit your manuscripts at

http://www.hindawi.com

\section{World Journal}

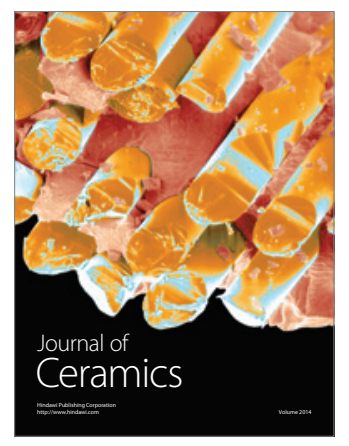

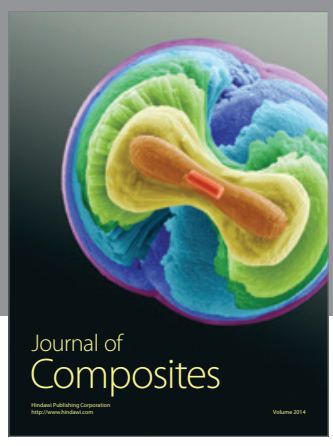
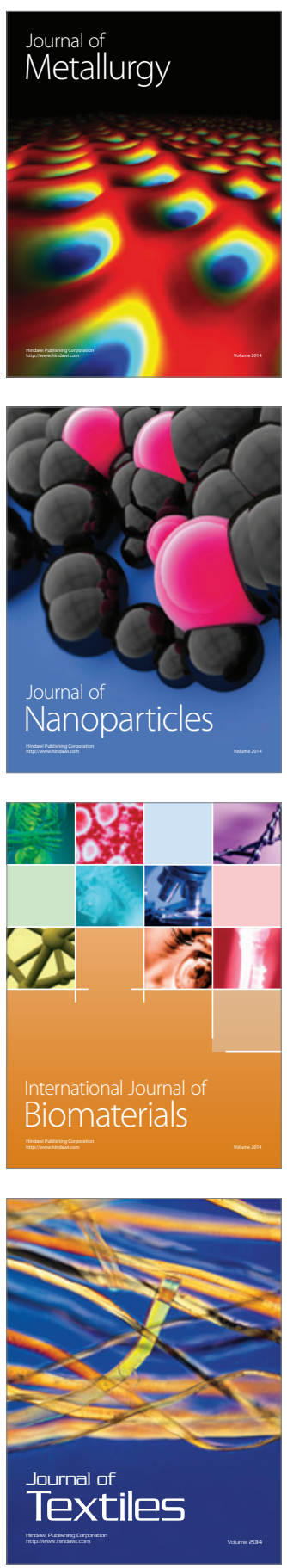